\title{
Bulut Tabanlı Mobil Diyabet Kontrol Uygulaması: Mobil Diyabetim
}

\author{
Pelin YILDIRIM ${ }^{1}$, Fatma BOZYİĞİT ${ }^{1}$, Mehmet Hilal ÖZCANHAN ${ }^{2}$, Semih UTKU $^{2}$ \\ ${ }^{1}$ Yazılım Mühendisliği Bölümü, Manisa Celal Bayar Üniversitesi, Manisa, Türkiye \\ ${ }^{2}$ Bilgisayar Mühendisliği Bölümü, Dokuz Eylül Üniversitesi, İzmir, Türkiye \\ pelin.yildirim@cbu.edu.tr, fatma.bozyigit@cbu.edu.tr, hozcanhan@cs.deu.edu.tr, semih@cs.deu.edu.tr \\ (Geliş/Received:26.07.2016; Kabul/Accepted:11.12.2016)
}

DOI: 10.17671/gazibtd.309295

\begin{abstract}
Özet- Yurdumuzda çok sayıda diyabet hastası bulunmaktadır. Bu hastalar diğer tüketiciler gibi tüm gün boyunca yoğun şekilde akıllı telefon ve mobil cihaz kullanmaktadır. Dolayısıyla, diyabet hastalarının kullandıkları mobil cihazlara özel bir yazılımla bu hastaların günlük yaşamlarını kolaylaştırmak mümkün görünmektedir. Bu çalışmada da diyabet hastalarına fiziksel veya tıbbi bir müdahalede bulunmadan, daha konforlu bir yaşam sürmelerine yardımcı olacak mobil bulut bilişim teknolojisine dayanan bir yazılım önerilmektedir. Hastaların diyabeti ilgilendiren günlük aktivitelerinin takibini kolaylaştıran özellikleriyle, geliştirilen çözümün hastaların iyileşme süreçlerine de yardımcı olacağına inanılmaktadır. Önerilen sistem birçok özellik yanında kullanıcılara özel, hem uyarıcı hem de hatırlatıcı mesajlar gönderebilmektedir. Benzer çözümlerle kıyaslandığında, önerilen yazılımın daha çok özelliği bir arada bulundurduğu ve iki yeni özellik içerdiği görülmektedir. Bir sonraki aşamada, çözümün yabancı dillere uyarlanması ve doktor gözetiminde gerçek denekler üzerinde teste tabi tutulması planlanmaktadır.
\end{abstract}

Anahtar Kelimeler - bulut bilişim, mobil bulut bilişim, diyabet, diyabet kontrol uygulaması

\section{A Cloud Based Mobile Diabetes Control Application: My Mobile Diabetes}

\begin{abstract}
There are a large number of diabetic patients, in our country. These patients use smart phones and mobile devices intensely throughout the day, as other consumers. Therefore, it seems possible to facilitate the daily lives of diabetes patients with special software for their mobile devices. In present study, medically non-intrusive, non-physical software based on mobile cloud computing that helps diabetic patients to have a more comfortable life is proposed. By facilitating the monitoring of patients' daily activities related to diabetes, it is believed that the developed solution can also help in mitigating some symptoms. Apart from multiple helpful features, the proposed system is capable of sending user specific warnings and alarms. When compared with similar solutions, the proposed system is observed to have more features in one solution and two new features. Future work is planned to translate the software into other languages and test the solution on real patients under doctor supervision.
\end{abstract}

Keywords - cloud computing, mobile cloud computing, diabetes, diabetes control application

\section{GIIRIŞ (INTRODUCTION)}

Diyabet, insülin hormonu eksikliği sonucu ortaya çıkan ve henüz kesin bir tedavi yöntemi bulunmayan kronik bir hastalıktır. 2015 verilerine göre dünya genelinde yaklaşı olarak 415 milyon kişiye diyabet tanısı konulmuş ve bu hastaların 5 milyonunun hayatını kaybettiği belirtilmiştir[1]. Diyabet hastalığı kendi içerisinde Tip 1 (insüline-bağımlı diyabet) ve Tip 2 (insüline bağımlı olmayan diyabet) olmak üzere iki ana gruba ayrılmaktadır. Günümüzde diyabet hastalığının bakımı hastanelerde doktor muayenesi ve kan tahlili sonuçlarına göre uygun ilaçların verilmesi, sağlıklı beslenme ve düzenli egzersizlerin yapılması ile sağlanmaktadır. Ancak nüfus yoğunluğu dolayısıyla, hasta sayısında sürekli artış olmakta ve hastanelerde diyabet hastalarının takibinin tümünde aynı başarının sağlanması mümkün olmamaktadır. Bazı diyabet hastalarının sağlık durumunun olumsuz seyretmesinin sebebi hastanelerdeki yoğunluktan dolayı tedavi ve tahlillerin gerektiği zamanda gerçekleştirilememesinden kaynaklanmaktadır. Buna hastaların randevularına ve diyabetle ilgili yapmaları gereken aktivitelere ilgi göstermemesi de eklenmektedir. $\mathrm{Bu}$ sebeplerden ötürü diyabet hastalarının tümünün sağlıklı beslenme, egzersiz yapma ve düzenli su tüketimleri düzene sokulamamaktadır. Bu durum, hastalık seyrinin kötüleşmesine ve ilave tıbbi müdahale, 
gerektirebilmektedir. Sonuç olarak da olmaması gereken ek masraflar ve akut durumlar ortaya çıkmaktadır. Ülkemizde Sağlık Bakanlığı, diyabet hastalığ konusundaki maliyet yükünü kontrol altına almak için çalışmalarını hassasiyetle sürdürmektedir. 2013 yılında IDF tarafindan yayınlanan 'Altıncı Diyabet Atlası' raporuna göre 2035 yılına kadar Türkiye dünyadaki diyabetli nüfus sayısının en yüksek olacağı ilk 10 ülke arasına girecektir [2]. Dolayısıyla, diyabet hastalarına günlük yaşamları sırasında yardımcı olabilecek kullanımı kolay, basit, her an yanlarında bulunabilecek araçlara ihtiyaç duyulmaktadır. Bu amaçla da, Sağlık Bakanlığı dijital teknolojilerin kullanımını diyabet hastalığı alanına da yaymayı ve personelinin diyabet hastalarına en iyi hizmeti sunabilmelerini hedeflemektedir.

Bulut bilişim ise günümüzün dijital teknolojisinin vardığg son noktadır. Bu teknoloji sanal bir sunucuda barındırılan uygulama ya da verilerin internet aracılığı ile her yerden erişilmesine olanak sağlayan büyük bir hizmetler bütünüdür. Bulut bilişim hizmeti müşterilerine otomatik ölçeklenebilirlik, kullandıkça öde seçeneği, her yerden erişilebilirlik, yüksek hacimli verilerin depolanması hizmetlerini sunmaktadır. En önemlisi ise, yüksek işlem gücüne sahip cihazlar ile başka yöntemlerle uzun süreye ihtiyaç duyulan veri analizinin, olabilecek en asgari sürede gerçekleştirmesini sağlamaktadır.

Günümüzde, bulut bilişim altyapısının öneminin farkına varılarak sağlık alanındaki kullanımının arttığ gözlemlenmektedir. Bulut bilişim teknolojisi kullanılarak oluşturulan sistemlerde amaç hastalara ait verilerin etkin bir şekilde saklanması, sürekli erișilebilir olması, hızlı analizlerle sonuç alınarak, sağlık hizmeti performansının azami düzeyde tutulmasıdır. Böylece hastanelerde meydana gelen yoğunluktan kaynaklı tedavi, tahlil faaliyetlerinin gecikmesinden doğabilecek olumsuz sonuçların hafifletilmesi hedeflenmektedir. Özellikle, 6 milyon civarında diyabet hastasının mevcut olduğu ülkemizde, diyabet alanında verilen hizmeti rahatlatacak ve yersiz masrafları azaltacak sistemlere ihtiyaç duyulduğu açıkça görülmektedir.

Teknoloji geliştikçe mobil cihazlara verilen önem artmış ve cihazların kullanımı yaygınlaşmıştır.. Akıllı telefon ve tablet bilgisayarlar gibi mobil cihazların özelliklerinde yaşanan gelişmeler mobil cihazların popülaritesini daha da arttırmıştır. Kullanım sayısında meydana gelen bu artış bulut bilişimin sağlamış olduğu ölçeklenebilirlik, yüksek işlem gücü, erişilebilirlik ve taşınabilirlik özelliklerinden dolayı bulut teknolojisinin kullanımına ihtiyaç doğurmuştur. Bunun sonucunda Mobil Bulut Bilişim (MBB) adı verilen bulut bilişim ile mobil cihazların birlikte çalışmasını sağlayan hizmetler bütünü kavramı ortaya çıkmıștır. MBB, mobil cihazların pil ömrünü uzatması ve genel işlem gücünü arttırması, mobil cihazlara yüksek veri depolama alanı sunması, ölçeklenebilirlik gibi hizmetlerle birçok avantaj sunmaktadır. Hâlihazırda bazı telefon operatör şirketleri de MBB hizmetinden faydalanmaktadır. MBB'in yaygın olarak kullanıldığ 1 sektörler ticaret, eğitim, sağlık ve oyun endüstrisidir. $\mathrm{Bu}$ çalışmada, yukarıda tanıtılan teknolojileri kullanarak hastalarına evlerinde, kendi durumlarını takip ve kayıt altında tutabilecekleri MBB tabanlı bir diyabet kontrol çözümü önerilmektedir. Öneri Sağlık Bakanlığı'nın hedeflerine varmasına yardımcı olacak bir çalışmayı oluşturmaktadır.

Çalışmanın geri kalan bölümlerinde, ikinci bölümde ilk olarak benzer çalışmalar incelenmekte, kullanılan yöntemler ve veri setleri ile çalışma prensipleri hakkında bilgiler verilmektedir. Üçüncü bölümde önerilen sistem ve geliştirilen yazılım uygulaması hakkında detaylı bilgi verilmiştir. Dördüncü bölümde önerilen çözüm değerlendirilirken, beşinci bölümde ise sonuç ve gelecekte yapılması planlanan çalışmalardan bahsedilmektedir.

\section{2. İLGİLI ÇALIŞMALAR (RELATED WORKS)}

Teknolojiyle birlikte sürekli olarak gelişen yazılım uygulamaları, sağlık alanında da oldukça yaygın bir şekilde kullanılmaktadır [3]. Sağlık alanında özellikle hastaların tedavilerini takip etmek, işlemlerini kolaylaştırmak ve pratik çözümler üretmek amacı ile birçok uygulama sunulmakta ve günden güne çeşitlilik ve kullanıcı yelpazesi büyümektedir. Özellikle, bulut bilişim sağlık alanında kullanılan uygulamalar içerisinde sıklıkla yer almaya başlamıştır. Örneğin, Hindistan'da yoğun nüfus sağlık alanındaki veri miktarında inanılmaz bir artışa sebep olmuş, bu da bulut bilişime olan ihtiyacı ortaya çıkarmıştır. PrincyMatlani ve Londhe sağlık hizmetini daha kaliteli ve etkin kullanmayı sağlamak adına, bulut bilişimin Hindistan'ın kırsal kesimlerinde tele-tıp alanında uygulanması üzerine bir çalışma gerçekleştirmiştir [4]. Bir diğer örnek, bir hastanenin pediatri ve doğum ile jinekoloji bölümlerinde kullanılmak üzere geliştirilen bilgi sistemidir [5]. Çalışmada hastanedeki her bir sağlı birimi için özel bulut bilişime dayanan altyapı oluşturulmuş ve hasta bilgilerinin birimler arası gönderilmesi için Health Level 7 (HL7) CDA standardını esas alan XML dosyaları kullanılmıştır. HL7 veri paylaşımında kullanılan standart kuralları barındırmaktadır. HL7 ile farklı ya da benzer ortamlardaki sağlık bilgi sistemlerinde bulunan verilerin belirli kurallar çerçevesinde paylaşılması hedeflenmektedir. Uygulamamızda farklı sistemlerin birbirleri ile uyumlu hale getirilmesi için HL7 kullanılmıştır.

2000'li y1llardan itibaren teknolojinin hızlı gelişsiminden en büyük payı alan kablosuz iletişimde herkesin alabileceği bir konuma gelen mobil cihazlar büyük kitleler tarafindan benimsenmiştir [6]. Mobil cihazlar için geliştirilen sağlıkla ilgili uygulamalar yaygın bir şekilde artmakta ve kullanılmaktadır. Mobil Sağlık Hizmeti (Mobile Healthcare) isimli bulut bilişim tabanlı mobil sağlık sistemi örneklerden biri olarak gösterilmektedir [7]. Çalışmada hastalara ait tıbbi dokümanların ve geçmiş bilgilerin, sistem içerisindeki paydaşlar ile eksiksiz ve sorunsuz bir şekilde paylaşıldığı iddia edilmektedir. İkinci olarak, Hoang ve Chen MoCAsH isimli bulut bilişim tabanlı mobil destekleyici sağlık hizmeti altyapısı örnek 
verilmektedir [8]. Araştırmacılar bu çalışmalarında bulut bilişimin avantajlarını sunarken, koordinat tabanl altyapıların geliştirme zorluğu, ağ seçme ve mobil cihaz güç limitleri gibi dezavantajlarından da bahsetmişlerdir. $\mathrm{Bu}$ alanda verilebilecek kapsamlı örneklerden biri de Tayvan'da bulunan dört farklı hastaneyi kapsayan bir sağlık ağı oluşturma çalışmasıdır [9]. Çalışmada, hastalara ait tüm verileri tek bir bulut sisteminde depolayarak dört ayrı düğüm arasında dağıtımı ve sorgulamayı kolaylaştıran bir sistem önerilmiştir. Manyetik rezonans ve röntgen gibi yüksek boyutlu verilere sahip hasta bilgilerinin sorunsuz şekilde depolanması ve hızlı şekilde sorgulanabilmesi mümkün hale geldiğinden, hastalar ve doktorlar arasındaki iletişimin arttırıldığı anlatılmaktadır. Çalışmanın bu yönleriyle sağlık hizmeti kalitesini artırdığı da savunulmaktadir.

Son zamanlarda birçok araştırmacı diyabet hastalığının tedavisine yardımcı olmak amacı ile bulut altyapısı içeren mobil uygulamalar geliştirmeye başlamıştır. Bunlardan biri de diyabet tedavisinin kısa vizite süreleri, sağlık personeline erişimin zorluğu, hasta sayısının fazla olması ve bu nedenle hasta takiplerinin zor bir şekilde gerçekleştirilmesi gibi zorlukları ortadan kaldırmayı amaçlayan mobil diyabet kontrol uygulamasıdır [10]. Çalışmada, hastanın glisemi kontrolünü ve insülin dozajını ayarlamasını sağlayan bulut bilişim tabanlı bir sistem önerilmektedir. Uygulamay1 kullanan hasta grubunun alyuvarlardaki hemoglobinin $(\mathrm{Hb})$ kan şekerine maruz kalması durumunda meydana gelen yapisal değişikliğin (glikozillenme) bir göstergesi olan HbAlc değerlerinin, kullanmayan gruba göre daha fazla düştüğü ve kullanıcılar tarafindan olumlu tepkiler aldığı belirtilmektedir. Başka bir çalışmada Few Touch Application isimli bir mobil diyabet bakım uygulaması anlatılmaktadır [11]. Uygulamada hastanın kan şekeri verilerinin otomatik transferi, k1sa hatırlatma mesajları gönderimi, diyabet günlüğü tutulması, fiziksel aktivite takibi gibi hizmetler sunulmaktadır. Uygulamalardan bir diğeri ise diyabet hastalarının glikozillenmiş hemoglobin seviyelerini düşürmeyi amaçlayan mobil takip uygulamasıdır [12]. Çalışmada, Maryland'da 163 diyabet hastası üzerinde yapılan araştırmalar ve uygulama ile hastaların glikozillenmiş hemoglobin seviyelerinde sağlanan düşüşler anlatılmaktadır. Farklı bir çalışmada da yetişkin diyabet hastalarının kan şekeri değerlerinin düşürülmesini hedefleyen bir mobil diyabet takip sistemi yer almaktadır [13]. Önerilen sistemle hastaların kan şekeri seviyelerinin geribildirimi, ilaç dozajlarının takibi yapılmaktadır. Çalışmalar sonucunda, uygulamayı kullananlarda kan şekeri değer düşüşü yaşandığı ve uygulamalarının hedefe ulaştığı bildirilmektedir.

Diyabet uygulamalarında genel olarak kullanıcıların şeker, tansiyon, öğün gibi bilgileri girdi olarak alınmakta ve değerler takip edilmektedir. Değerler belli eşiklerin üzerinde veya altında seyrettiği zaman hasta uyarılmaktadır.

\section{3. ÖNERİLEN ÇÖZÜM (PROPOSED SOLUTION)}

Önerilen çözüm diyabet hastalarının belirlenmiş saatlerde yapmaları gereken ölçüm ve faaliyetlerin (egzersiz yapmak ve su içmek gibi) zamanında yapılmasını sağlamaya yönelik hem sunucu hem de istemci yazılımlarından oluşan bir uygulamadır.

\subsection{Motivasyon (Motivation)}

Önerilen MBB destekli "Mobil Diyabetim" (MD) sistemi üç ana bölümden oluşmaktadır:

i. Hastanın günlük tükettiği su miktarının hesaplanması ve günlük limitin altında su tüketilmesi durumunda hastaya hatırlatıcı mesajların gönderilmesi,

ii. Hastanın her öğün tüketmiş olduğu gıda verilerinin ve yapmış olduğu egzersizlerin sisteme girişinin sağlanması ve hasta tarafından bu verilerin sisteme girişinin unutulması durumunda belirli zaman aralıkları ile hatırlatıcı mesajların gönderilmesi,

iii. Ölçülen kan şekeri ve tansiyon değerlerinin sisteme kaydedilerek kan şekeri ve tansiyon günlüğü oluşturması, değerlerin sisteme girişinin unutulması durumunda belirli zaman aralıkları ile hatırlatıcı mesajların gönderilmesi.

MD sayesinde diyabet hastalarına ait veriler bulut sistemi üzerinde tutulacak ve etkin bir şekilde değerlendirme yapılması sağlanacaktır.

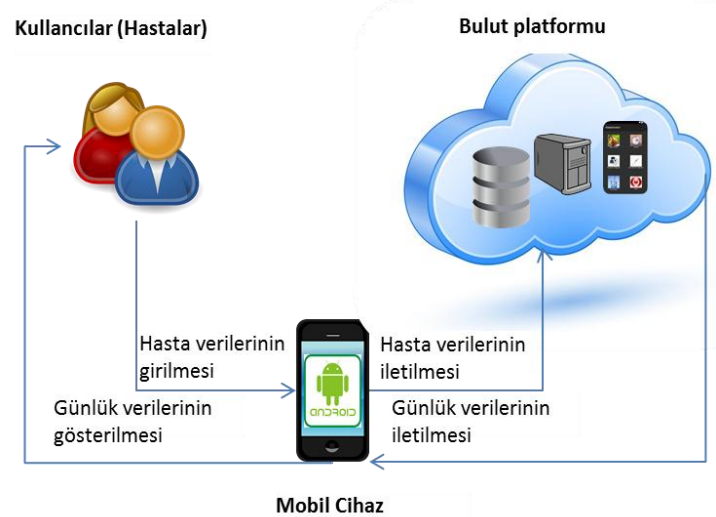

Şekil 1. Sistem mimarisi (System architecture)

\subsection{Mobil Diyabet Yazılım Sistemi (Mobile Diabetes Software System)}

Şekil 1'de, bulut tabanlı MD sistemin mimari yapısı gösterilmektedir. Sistem üç ana bölümden oluşmaktadır. Birinci bölümde, kullanıcıların (hastalar) gerekli tüm bilgileri (kişisel bilgiler, kan şekeri, tansiyon, su miktarı, öğün ve egzersiz gibi) mobil cihaza girmesi işlemi gerçekleştirilmektedir. İkinci bölümde, mobil cihaz üzerinden bilgilerin bulut platformuna iletilmesi, "Günlük" hizmeti ile de bulut platformunda tutulan bu bilgilerin tekrar kullanıcıya sunulması gerçekleşmektedir. Son bölümde ise, mobil cihaz aracılığıyla sayısız hasta 
bilgilerinin yer ve zamandan bağımsız bulut bilişim platformu vasitasıyla merkezi bir veri tabanında barındırılması sağlanmaktadır. Veri tabanında tutulan bilgilere, mobil uygulama tarafından her istenildiğinde hızlı bir şekilde erişilebilmektedir.

MD sadece sisteme daha önceden kayıtlı bulunan hastalar tarafindan kullanılabilir bir uygulamadır. Bu sebeple, uygulama içerisinde kullanıcıyı ilk olarak Şekil 2 (a)'da gösterilen kullanıcı giriş ekranı karşılamaktadır. Önceden sisteme üye bir kullanıcı, mail adresi ve şifre bilgileriyle "Giriş" butonuna tıklayarak sisteme erişebilmektedir. Eğer kullanıcı sisteme daha önceden kayıt olmamış ise, "Kayıt Ol" butonu yardımıyla kayıt ekranına yönlendirilerek hastanın sisteme kayıt olması sağlanmaktadır. Hasta, isim soyadı, mail adresi, şifre ve telefon numarası bilgilerini girerek sisteme kayıt olmaktadır. Sisteme giriş yapan kullanıcı Şekil 2 (b)'de gösterilen Menü ekranına ulaşmaktadır. MD bu menü yardımı ile hastalara altı temel hizmet sunmaktadır. Sunulan hizmetler aşağıda detaylı şekilde anlatılmaktadır.

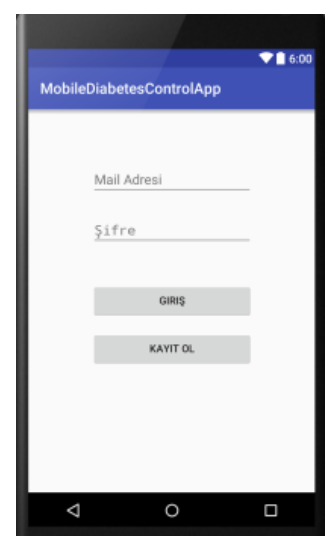

(a)

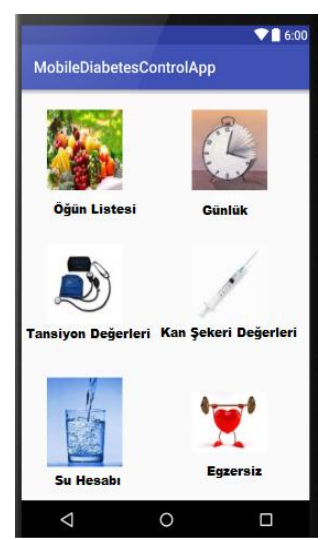

(b)
Şekil 2. (a) Kullanıcı giriş ekranı (User login screen) (b) Menü ekranı (Menu screen)

\subsubsection{Kan Şekeri Değerleri (Blood Glucose Values)}

"Kan şekeri değerleri” butonuna tıklayan kullanıcı Şekil 3 (a)'da gösterilen kan şekeri ekranına yönlendirilmektedir. Bu ekranda hasta ölçmüş olduğu kan şekeri değerlerini sisteme girmektedir. Hasta tarafindan değerlerin sisteme girişinin unutulması durumunda belirli zaman aralıkları ile uygulama tarafindan hastaya hatırlatıcı mesajlar gönderilmektedir. Hasta bilgilerini girdiği zaman mesaj gönderimi sona ermekte, ancak boş geçen bilgi girişleri veri tabanına "bilgi girilmedi" şeklinde yansitılmaktadır.

\subsubsection{Tansiyon Değgerleri (Blood Pressure Values)}

"Tansiyon değerleri" butonuna tıklayan kullanıcı ise Şekil 3 (b)'de gösterilen tansiyon değerleri ekranına yönlendirilmektedir. Hasta ölçmüş olduğu büyük ve küçük tansiyon değerlerini bu ekran yardımı ile sisteme kaydetmektedir. Kan şekeri değerleri ekranında olduğu gibi, bu ekranda da hasta tarafindan değerlerin sisteme girişinin unutulması durumunda belirli zaman aralıkları ile hatırlatıcı mesajlar gönderilmektedir.

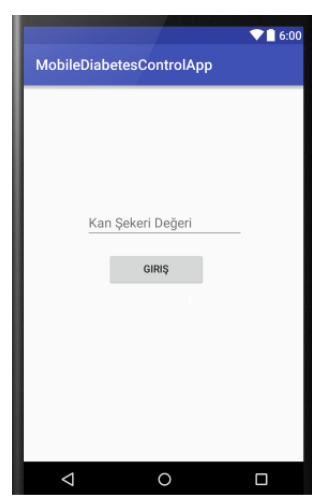

(a)

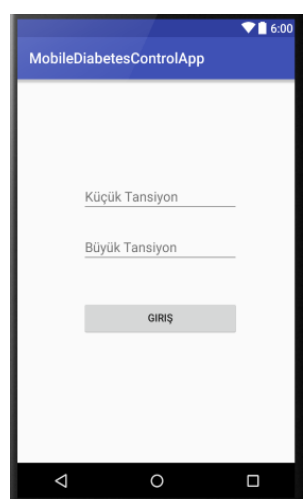

(b)
Şekil 3. (a) Kan şekeri ekranı (Blood glucose screen) (b) Tansiyon değerleri ekranı (Blood pressure screen)

\subsection{3. Öğ̈̈n Listesi (Meal List)}

Kullanıcı "Öğün Listesi” butonuna tıklayarak Şekil 4 (a)'daki öğün listesi ekranına ulaşmaktadır. Kullanıcı bu ekran üzerinde seçmiş olduğu öğün türüne göre tükettiği besinleri girerek sisteme kaydetmektedir. Kullanıcının öğün bilgilerini girmeyi unuttuğu durumlarda da yine hatırlatıcı mesajlar ile kullanıcı uyarılmaktadır.

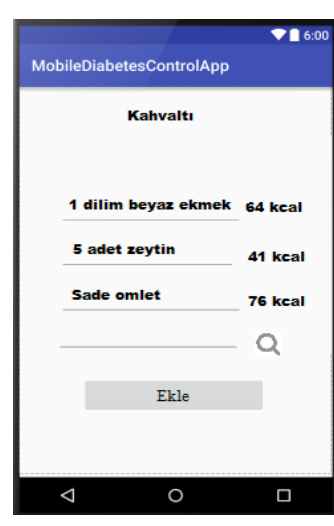

(a)

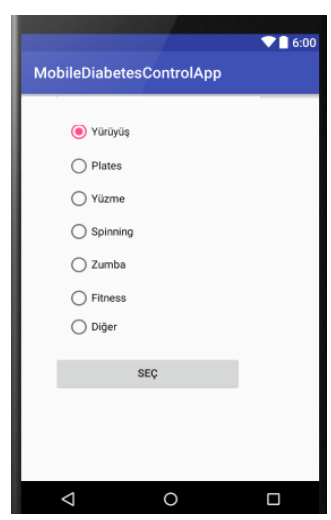

(b)
Şekil 4. (a) Öğün listesi ekranı (Meal list screen)

(b) Egzersiz ekranı (Exercise screen)

\subsubsection{Egzersiz Bilgileri (Exercise Information)}


Hasta "Egzersiz" butonuna tıklayarak Şekil 4 (b)'deki egzersiz ekranına yönlendirilmektedir. Kullanıcı liste içerisindeki egzersiz türünü seçip, yapmış olduğu set sayısını girerek sisteme kaydetmektedir. Kullanıcı yetersiz egzersiz yapması veya egzersiz bilgilerini girmeyi unuttuğu durumlarda da yine hatırlatıcı mesajlar ile uyarılmaktadır.

\subsubsection{Su Tüketimi Takibi (Water Consumption Tracking)}

Hasta "Su hesabı" butonuna tıklayarak Şekil 5 (a)'da gösterilen su tüketimi ekranı üzerinden günlük tüketilen su miktarını bardak cinsinden girerek sisteme kaydedebilmektedir. MD girilen su bilgilerini belirli aralıklarla kontrol edip hastanın yeterli miktarda su tüketmemesi veya bilgileri sisteme girmeyi unuttuğu durumlarda hastaya hatırlatıcı mesajlar göndermektedir.

Görüldüğü gibi hasta birçok hatırlatıcı mesaj almakta, uyarılara uyması durumunda da hastalığının seyrini olumlu yönde etkileyecek gerekli tedbirleri yerine getirmektedir.

\subsubsection{Günlük (Diary)}

“Günlük” butonuna tıklayan kullanıcı, Şekil 5 (b)'de gösterilen günlük ekranına yönlendirilir. Bu ekran üzerinde daha önceden sisteme girmiş olduğu tüm değerleri (kan şekeri, tansiyon, su miktarı, kalori ve egzersiz bilgileri gibi) gün bazında listeleyebilmektedir.

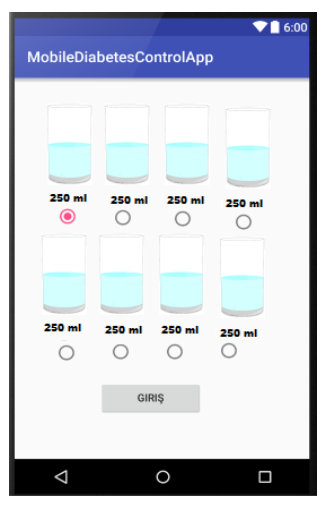

(a)

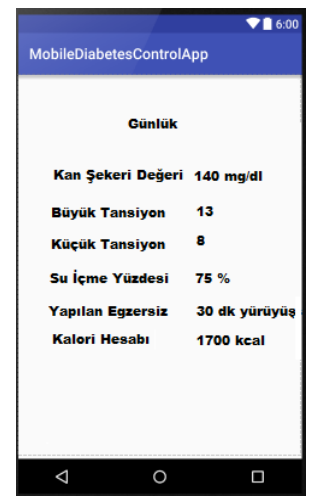

(b)
Şekil 5. (a) Su tüketimi ekranı (Water consumption screen) (b) Günlük ekranı (Diary screen)

Günlüğünü kontrol eden ve MD uygulamasından ayrılmak isteyen kullanıcı "Çıkış" butonuna tıklayarak sistemden güvenli bir şekilde çıkışını gerçekleştirebilmektedir.

\section{DEĞERLENDİRME (EVALUATION)}

Diyabet hastalarının hayatlarını kolaylaştırmak ve iyileşme süreçlerine yardımcı olmak amacıyla önerilen çözümlerin değerlendirilmelerinde öncelikle sınıflandırmaları yapılmaktadır. Çözüm önerilerinin sınıflandırmasında diyabet takip uygulaması olup olmadıkları, mobil cihazlar için tasarlanmış olup olmadıkları ve bulut bilişim altyapısı kullanmayı önerip önermedikleri değerlendirilmektedir. Tablo 1'de, benzer çalışmalar ve MD önerisinin bu üç konudaki durumları kıyaslanmaktadır. Tablo'da bulut bilişimi sağlık hizmetleri alanında öneren çalışmalara yer verilmiştir. Ancak, incelenen çalışmalardan sadece [10], [11], [12], [13] ve MD çalışmalarının MBB tabanlı mobil diyabet takip uygulaması oldukları görülmektedir.

Sundukları hizmetler açısından da önerilen çözümlerin değerlendirilmeleri gerekmektedir. Diyabet hastalarının hayatlarını kolaylaştıracağına ve iyileşme süreçlerine yardımcı olacağına inanılan hizmetler yaygın olarak kan şekeri ve tansiyon bilgilerinin tutulması, egzersiz takibi, su tüketim takibi, hatırlatıcı veya uyarıcı mesajlar verilmesi şeklinde listelenmektedir. İncelenen çalışmaların sunduğu hizmetler de Tablo 1'de karşılaştırılmıştır. Çalışma [4], [5] ve [9] bulut bilişimin sağlık hizmetlerinde kullanılmasını önermekle beraber mobil teknolojisinin kullanımı bu çalışmalarda yer almamaktadir.

Olmayan MBB özelliğine bağlı olarak, bu çalışmaların sunduğu mobil günlük veya takip uygulamaları da bulunmamaktadır. Sağlık hizmetlerinde hastalara yardımcı olmak için MBB kullanılmasını öneren çalışma [7] ve [8] ise diyabet hastalarını özellikle hedef alan bir öneri içermemektedir. Çalışma [12], diyabet hastalarına yönelik bir MBB uygulaması olmasına rağmen, hastaların şeker seviyesi takibi konusunda tıbbi bir çalışmayı oluşturmakta, fakat kullanıcılarına başka hizmetler sunmamaktadır. Çalışma [10] ve [13] ise sadece günlük hizmeti sunan birer yazılım uygulaması önermektedir. Direk olarak diyabet hastalarını hedefleyen MBB kullanımını öneren ve en fazla hizmeti sunan iki uygulama çalışma [11] ve MD olarak görülmektedir. Çalışma [11] günlük, egzersiz takibi ve su tüketimi takibi hizmetlerini sunsa da, MD ilave olarak uyarıcı mesajlar verme ve düzenli hatırlatmalar yapan özellikleriyle çalışma [11]'den daha fazla hizmet sunmuş olmaktadır. Ancak çalışma [11]'in önerilen MD gibi HL7 desteği bulunmamaktadır. 
Tablo 1. Uygulama karşılaştırılma tablosu (Application comparison table)

\begin{tabular}{|c|c|c|c|c|c|c|c|c|}
\hline \multirow[b]{2}{*}{ Çalışmalar } & \multicolumn{8}{|c|}{ Sunulan Hizmetler } \\
\hline & $\begin{array}{c}\text { Diyabet Takip } \\
\text { Uygulaması }\end{array}$ & $\begin{array}{c}\text { Mobil } \\
\text { uygulama }\end{array}$ & $\begin{array}{c}\text { Bulut } \\
\text { altyapısı }\end{array}$ & Günlük & Egzersiz & $\begin{array}{c}\text { Su } \\
\text { Tüketimi }\end{array}$ & HL7 & $\begin{array}{c}\text { Uyarıcı } \\
\text { Mesajlar(Su } \\
\text { ve Egzersiz } \\
\text { Hatırlatıcı) }\end{array}$ \\
\hline$[4]$ & $\mathrm{X}$ & $\mathrm{X}$ & $\sqrt{ }$ & $\mathrm{X}$ & $\mathrm{X}$ & $\mathrm{X}$ & $\mathrm{X}$ & $\mathrm{X}$ \\
\hline [5] & $\mathrm{X}$ & $\mathrm{X}$ & $\sqrt{ }$ & $\mathrm{X}$ & $\mathrm{X}$ & $\mathrm{X}$ & $\sqrt{ }$ & $\mathrm{X}$ \\
\hline [7] & $\mathrm{X}$ & $\sqrt{ }$ & $\sqrt{ }$ & $\mathrm{X}$ & $\mathrm{X}$ & $\mathrm{X}$ & $\mathrm{X}$ & $\mathrm{X}$ \\
\hline [8] & $\mathrm{X}$ & $\sqrt{ }$ & $\sqrt{ }$ & $\mathrm{X}$ & $\mathrm{X}$ & $\mathrm{X}$ & $\mathrm{X}$ & $\mathrm{X}$ \\
\hline [9] & $\mathrm{X}$ & $\mathrm{X}$ & $\sqrt{ }$ & $\mathrm{X}$ & $\mathrm{X}$ & $\mathrm{X}$ & $\mathrm{X}$ & $\mathrm{X}$ \\
\hline [10] & $\sqrt{ }$ & $\sqrt{ }$ & $\sqrt{ }$ & $\sqrt{ }$ & $\mathrm{X}$ & $\mathrm{X}$ & $\mathrm{X}$ & $\mathrm{X}$ \\
\hline [11] & $\sqrt{ }$ & $\sqrt{ }$ & $\sqrt{ }$ & $\sqrt{ }$ & $\sqrt{ }$ & $\sqrt{ }$ & $\mathrm{X}$ & $\mathrm{X}$ \\
\hline [12] & $\sqrt{ }$ & $\sqrt{ }$ & $\sqrt{ }$ & $\mathrm{X}$ & $\mathrm{X}$ & $\mathrm{X}$ & $\mathrm{X}$ & $\mathrm{X}$ \\
\hline [13] & $\sqrt{ }$ & $\sqrt{ }$ & $\sqrt{ }$ & $\sqrt{ }$ & $\mathrm{X}$ & $\mathrm{X}$ & $\mathrm{X}$ & $\mathrm{X}$ \\
\hline MD & $\sqrt{ }$ & $\sqrt{ }$ & $\sqrt{ }$ & $\sqrt{ }$ & $\sqrt{ }$ & $\sqrt{ }$ & $\sqrt{ }$ & $\sqrt{ }$ \\
\hline
\end{tabular}

MD kullanan bir diyabet hastası kan şekeri değerinin yükselme eğilimine girdiği, su tüketimi veya egzersiz düzeyinin yeterli düzeyde olmadığı hakkında uyarılar almaktadır. Ayrıca, MD kullanıcıları geçmiş faaliyetlerini düzenli olarak gerçekleştirseler de, faaliyet programlarındaki saatlere uygun olarak faaliyetleriyle ilgili hatırlatmalar almaya devam etmektedirler. $\mathrm{Bu}$ sayede MD kullanıcıları çok öneme sahip olan günlük ihtiyaçları hakkında sürekli mesajlar almaktadır. MD sahip olduğu özelliklerle diyabet hastalarına sürekli bir yardımcı görevi gören bir şahıs gibi, günün her anında arkadaşlık etmektedir.

\section{SONUÇ (CONLUSION)}

Günümüzde akıllı telefon ve mobil cihazlar her yaştaki diyabet hastası kullanıcı tarafindan yoğun olarak kullanılmaktadır. Çalışmamızda diyabet hastası olanların hayatlarını kolaylaştırmak ve iyileşme süreçlerine yardımc olmak amaciyla kullanıcı dostu bir yazılım uygulaması önerilmektedir. Önerilen yazılım MBB teknolojisi kullanmakta ve hem sunucu hem de istemci tarafında uygulamalar içermektedir. Önerilen yazılımın diyabet hastalarına sunulan benzer çözümlerdeki uygulamalardan daha fazla hizmet sunan özellikleri bulunmaktadır. Önerilen MD'in birçok özelliği barındırıyor olması, bir diyabet hastasının başka yazılımlara gerek kalmadan çoğu ihtiyacını karşılamasını sağlamaktadır. Benzer çalışmalarla yapılan kıyaslamalar önerilen yazılımın sahip olduğu özelliklerin diğer çalışmalara nazaran daha fazla olduğunu göstermektedir. Sahip olduğu HL7 özelliğiyle de, MD’nin hem yurtiçi hem de yurtdışındaki diyabet hastalarına yardımcı olabileceği değerlendirilmektedir. Çözümün başka dillere uyarlanması ve doktor gözetiminde kullanıma sunularak istatistiki çalışmaların yapılması için girişimler devam etmektedir.

\section{KAYNAKLAR (REFERENCES)}

[1]Internet: Türk diyabet cemiyeti, http://www.diabetcemiyeti.org,13.05.2016.

[2]Internet: Diabetesatlas, http://www. diabetesatlas.org,13.05.2016.

[3] J. E. Bibault, P. Blanchard, B. Dubray, E. Lartigau, A. Zadeh, "ELQ: A biologically-equivalent dose calculator available on iPhone, Android, and the web", Practical Radiation, 1(3), 212-213, 2011.

[4] Ms. PrincyMatlani, N. D. Londhe, "A cloud computing based telemedicine service", IEEE Point-of-Care Healthcare Technologies (PHT), Bangalore, India, 326330, 1618 January, 2013.

[5] O. S. Lupşe, M. M. Vida, L. S. Tivadar, "Cloud computing and interoperability in healthcare information systems", INTELLI : The First International Conference on Ontelligent Systems and Applications, Chamonix, France, 8185, 2904 April-May, 2012.

[6] N. Keskin, H. Kılınç, "Mobil öğrenme uygulamalarına yönelik geliştirme platformlarının karşılaştırılması ve örnek uygulamalar", Açıöğretim Uygulamaları ve Araştırmaları Dergisi, 1(3), 68-90, 2015. 
[7] C. K. Yahaya, W. H. Hassa, "Context-Awareness in Mobile Cloud Computing: Healthcare", The Society of Digital Information and Wireless Communications (SDIWC), 30-34, 2013.

[8] D. B. Hoang, L. Chen, "Mobile cloud for Assistive Healthcare (MoCAsH)", IEEE Asia-Pacific Services Computing Conference, Hangzhou, China, 325331, 0610 December, 2010.

[9] S. J. Weng, L. S. Lai, D. Gotcher, H. H. Wu, Y. Y. Xu, C. W. Yang, "Cloud Image Data Center for Healthcare Network in Taiwan", Journal of Medical Systems, 40(4), 1-11, 2016.

[10] W. C. Hsu, K. H. Lau, R. Huang, H. Le, S. Gilroy, M. Abrahamson, J. Moore, "Utilization of a Cloud-Based Diabetes Management Program for Insulin Initiation and Titration Enables Collaborative Decision Making Between Healthcare Providers and Patients", Diabetes Technology \& Therapeutics, 18(2), 59-67, 2016.
[11] E. Arsand, D. H. Froisland, S. O. Skrovseth, T. Chomutare, N. Tatara, G. Hartvigsen, J. T. Tufano, "Mobile health applications to assist patients with diabetes: lessons learned and design implications", Journal of Diabetes Science and Technology, 6(5), 1197-1206, 2012.

[12] C. Quinn, M. Shardell, M. Terrin, E. Barr, S. Ballew, A. GruberBaldini, "Cluster-randomized trial of a mobile phone personalized behavioral intervention for blood glucose control", Diabetes care, 36(11), 1934-1942, 2013.

[13] C. C. Quinn, S. S. Clough, J. M. Minor, D. Lender, M. C. Okafor, A. Gruber-Baldini, "WellDoc TM mobile diabetes management Randomized controlled trial: Change in clinical and behavioral outcomes and patient and physician satisfaction", Diabetes Technology \& Therapeutics, 10(3), 160-168, 2008. 